\title{
Use of null models to assess patterns of size class migrations in the copepod Zausodes arenicolus
}

\author{
Susan K. Service*, Keith Walters* \\ Department of Biology, University of South Florida, Tampa, Florida 33620, USA
}

\begin{abstract}
Size-specific patterns in the migration (emergence) of a sediment-associated harpacticoid copepod were examined in a subtidal seagrass habitat using a null model approach. Size frequency distributions of all Zausodes arenicolus Wilson, 1932 and of females, males and copepodites collected on 2 dates in the water column and sediment were analyzed. Migrating and non-migrating size frequency distributions for all $Z$. arenicolus were different only in November 1983 . The migration of significantly larger females in November 1983 influenced the size distribution for all migrating $Z$. arenicolus and was not the result of random emergence from the sediment. Size distributions of migrating and nonmigrating males and copepodites were not significantly different and could not be distinguished from null distributions on either date. Evidence for size influencing migratory behavior of $Z$. arenicolus is weak, but the non-random migration of larger females on one date requires further investigation.
\end{abstract}

\section{INTRODUCTION}

The size of an individual often influences migratory behavior in marine organisms, especially Crustacea (Sulkin 1984, Epifanio 1988). Typically, the effects of body size on migration are inferred from differences in water column vertical distributions of different sized individuals (Huntley \& Brooks 1982, Rothlisberg 1982, Williams \& Fragopoulu 1985). Size influences mating success in several arthropod taxa (Ward 1983, Lawrence 1987, Grad \& Maly 1988), and increased mating contacts is proposed as one advantage of vertical migration for benthic species (Preece 1971, Williams \& Bynum 1972), including harpacticoid copepods (Bell et al. 1988). Size-selective predation also can influence migrations of freshwater insects (Allan 1978) and crustaceans (Newman \& Waters 1984, Malmqvist \& Sjostrom 1987), and marine zooplankters (Robertson \& Howard 1978, Fancett \& Kimmerer 1985). Based on observed relationships between body size and migration, a number of deterministic hypotheses, for example differential predation, have been proposed to explain size-related differences in migration (Huntley \& Brooks 1982, Ward 1983, Lampert 1987).

An alternative to concluding that size differences in

- Present address: University of Georgia Marine Institute, Sapelo Island, Georgia 31327, USA migration result from deterministic factors would be to suggest that observed distributions simply result from non-deterministic or random factors. The role of nondeterministic factors in shaping observed patterns can be examined using a null model. Although the term null model was coined by Colwell \& Winkler (1983), equivalent models have been in use for some time (see Williams 1947). While most hypotheses assume a deterministic cause, null model hypotheses investigate the contribution of stochastic factors in shaping observed patterns. Null models can serve as controls for nonexperimental data by evaluating the role of chance in structuring patterns (Strong 1980).

Procedures for constructing a null model will vary considerably from study to study. Fundamentally, null models are used to generate randomly a new data set that is compared statistically with data actually collected. The newly constructed data set is generated by Monte Carlo simulations, a series of random draws with or without replacement, from a previously identified source pool that usually consists of a combination of all data collected. Numbers drawn from a source pool in simulations can be classified by variables such as species names, flowering times, or body sizes. Harvey et al. (1983) and Nitecki \& Hoffman (1987) contain reviews and examples of the use of null models.

Our study applies a null model approach to analyze behavioral differences in migration among size classes 
of a sediment-associated harpacticoid copepod, Zausodes arenicolus Wilson, 1932. This is a very mobile species in subtropical seagrass beds and is commonly found in phytal (Bell et al. 1987), benthic and pelagic (Walters \& Bell 1986) habitats. Pelagic occurrences of $Z$. arenicolus in subtidal sand and seagrass habitats typically result from active migration into the water column (Walters \& Bell 1986, Walters 1987). Z. arenicolus commonly is involved in precocious clasping (Kern et al. 1984), and migration has been linked to reproductive activity (Bell et al. 1988). Preliminary observations of $Z$. arenicolus migrations indicated that behavioral differences among size classes may exist (Walters unpubl.). In this paper, we examine the size frequency distributions of migrating and non-migrating $Z$. arenicolus using a null model approach and ask whether the migratory behavior of this species is influenced by size.

\section{METHODS}

Field methods. Zausodes arenicolus that migrated into the water column were collected from a Thalassia testudinum (König) seagrass bed near the mouth of Tampa Bay, Florida, USA, on 23 November 1983 and 17 November 1984. Dates were selected to coincide with seasonal increases in $Z$. arenicolus sediment densities and numbers migrating (Walters unpubl.). An emergence trap (Walters 1988) was used to collect migrating harpacticoids. The trap consisted of a $10.4 \mathrm{~cm}$ diameter PVC base pushed $15 \mathrm{~cm}$ into the sediment, and a clear acrylic catch-tube positioned securely on the PVC base. An inverted, transparent funnel in the base of the catch-tube and a $0.063 \mathrm{~mm}$ mesh cap directed movement into and restricted movement out of the catch-tube, respectively. Organisms had to swim $15 \mathrm{~cm}$ from the sediment-water interface to be collected in the catch-tube. A cork stoppered the funnel while the catch-tube was filled with $0.063 \mathrm{~mm}$ filtered seawater and placed on the PVC base. Sampling periods began when the cork was removed.

On each date, 10 to 12 emergence traps were placed in an ca $2 \mathrm{~m}^{2}$ area of the seagrass bed immediately before sunset, since sunset represents the time of maximum harpacticoid migration within Tampa Bay seagrass habitats (Walters 1987, 1988). Water depth during $2 \mathrm{~h}$ sampling periods was ca $1 \mathrm{~m}$. Migrating (within catch-tube) and non-migrating (within sediment) harpacticoids were collected at the end of a $2 \mathrm{~h}$ sampling period. Non-migrating harpacticoids were estimated from 3 subsamples which consisted of a $2.7 \mathrm{~cm}$ diameter core pushed $3 \mathrm{~cm}$ into the sediment within the PVC base of each trap. All catch-tube and sediment samples were preserved in $10 \%$ buffered formalin and seawater, with Rose Bengal added to facilitate sorting.
Laboratory methods. Non-migrating harpacticoids were separated from sediments by the shake and decant method (Wieser 1960), and all harpacticoids sorted at $25 \times$ under a dissecting microscope. Individual Zausodes arenicolus were removed from samples, mounted in glycerin and measured with an ocular micrometer under a compound microscope. All individuals were measured from the anterior margin of the cephalothorax (excluding rostrum) to the posterior end of the anal somite (excluding terminal setae). Later stage copepodites and adult copepods were sexed, and observations regarding the number of gravid females and clasping pairs per sample were recorded.

Statistical analyses. To compare the overall size frequency distributions of migrating and non-migrating Zausodes arenicolus within the seagrass bed, we combined individuals collected in different traps. In 1983, size frequency distributions representing the sum of $Z$. arenicolus from 10 traps were analyzed. Size frequency analyses of 1984 data only used 4 of 12 emergence traps collected because 4 traps adequately represented the size frequency distribution of migrating and nonmigrating harpacticoids in 1983; there was no statistical difference between distributions from 4 and $>4$ traps [Kolmogorov-Smirnov 2-sample test, (K-S) Z = $1.276, \mathrm{p}>0.05]$. We realize population size distributions may change yearly, but believe our method was a reasonable approach to reduce the 1984 sample size without loss of information.

The frequency of non-migrating individuals and the total frequency, migrating and non-migrating, of a given size class were adjusted for area sampled because non-migrating Zausodes arenicolus were estimated from 3 subsamples in each trap. Total frequency of a given size class was calculated by:

$$
\mathrm{f}_{\mathrm{i}}=\mathrm{m}_{\mathrm{i}}+\mathrm{s}_{\mathrm{i}}\left(5.2^{2} / 3\left(1.35^{2}\right)\right)
$$

where $\mathrm{f}_{\mathrm{i}}=$ frequency of size class $\mathrm{i}$ (water column + sediment); $\mathrm{m}_{\mathrm{i}}=$ frequency of size class $\mathrm{i}$ in the water column; $\mathrm{s}_{\mathrm{i}}=$ frequency of size class $\mathrm{i}$ in the sediment; $5.2=$ radius of water column trap; $1.35=$ radius of sediment core subsample.

Zausodes arenicolus were grouped into $20 \mu \mathrm{m}$ size classes and the size frequency distributions of migrating and non-migrating individuals compared on each date using the K-S 2-sample test at the 0.05 level of significance (Sokal \& Rohlf 1981). Analyses also were run separately for males and females because $Z$. arenicolus is sexually dimorphic with respect to size as well as structure. Comparison of null-model-generated size frequency distributions (see below) for migrating $Z$. arenicolus were also compared with observed water column distributions using the K-S 2-sample test.

Null model techniques. Null model size distributions of migrating Zausodes arenicolus were generated by 
Monte Carlo simulation from a source pool produced by summing actual water column and sediment numbers within each size class (Table 1). The null distribution generated from the model consisted of individuals chosen from a size pool weighted by the actual proportion of individuals in each size class. Distributions generated by the null model were compared to actual distributions of migrators. The null model hypothesis tests whether observed distributions of migrating $Z$. arenicolus could have been generated by random factors; i.e. the numbers of a given size class in the water column simply reflected the proportion of that size class in the sediment. In summing together water column and sediment copepods to produce the source pool, the model assumes all migrators came from the sediment population, and that the source pool is representative of all available migrating size classes and relative abundances of $Z$. arenicolus in each size class. Given the haphazard positioning of traps in the seagrass bed and the large sample size of measured $Z$. arenicolus (3511 in 1983 and 1032 in 1984), assumptions about sampling all size classes and accurately determining the relative abundance of each size class appear to have been satisfied.

Monte Carlo simulations were written using SPSS and run on the IBM 3033 at the University of South Florida Regional Computer Center and the IBM 3081 at the University of South Carolina. In each simulation, a different random number sequence was used to ensure independence of the results. Individuals were sampled from each source pool without replacement; once an individual copepod migrated into the water, sediment re-entry through the catch-tube funnel was unlikely. Numbers drawn from the source pool for each model were determined by the actual numbers of Zausodes arenicolus found to have migrated into the water column.

\section{RESULTS}

Zausodes arenicolus were 19.3 and $21.0 \%$ of the total harpacticoid assemblage on sampling dates and represented a greater percentage of the Tampa Bay seagrass harpacticoid assemblage compared to other November dates (Table 2). Although typically not a predominant migrating species in subtidal habitats (Walters 1987), November percentages of migrating $Z$. arenicolus were similar to migration percentages of the entire harpacticoid assemblage (Table 2). In the present study, $8.9 \%$ of the total harpacticoid sediment population migrated into the water column during the 1983 postsunset sampling period, while in 1984 only $5.5 \%$ migrated. For $Z$. arenicolus, 20.1 and $5.2 \%$ of the sediment-associated population migrated into the water column in 1983 and 1984, respectively (Table 2). In both years, females predominated over males in the sediment, while males predominated in the water column in 1983 and females in 1984 (Table 3). Equal proportions of gravid and non-gravid females were found in the water column and sediment on both dates; however a greater percentage of females were gravid in 1983 than 1984 (Table 3). A greater percentage of the total $Z$. arenicolus population was involved in precopulatory clasping in the water column in 1984 compared to 1983 (Table 3).

The size distributions of migrating and non-migrating Zausodes arenicolus (Fig. 1) were significantly different in 1983 (K-S, $\mathrm{Z}=2.183, \mathrm{p}<0.05$ ) but not in $1984(\mathrm{~K}-\mathrm{S}, \mathrm{Z}=1.216, \mathrm{p}>0.05)$. Examining the data catagorized by sex and stage, the 1983 size distribution of females in the water column was significantly different from that in the sediment (K-S, $\mathrm{Z}=4.538, \mathrm{p}<0.05$ ). The size distribution of migrating females was skewed towards larger size classes in 1983 (Fig. 2). Females between 377 and $439 \mu \mathrm{m}$ comprised $28 \%$ of all migra-

Table 1. Zausodes arenicolus. Example of source pool generation for size-class null models using data from the male size frequency distribution in 1983. Comparison of the actual number collected in the water column (Column 2) with the randomly generated water column distribution (Column 5) tests whether observed size-class migration patterns are significantly different from migration pattern expected under the null model

\begin{tabular}{|ccccc|}
\hline $\begin{array}{c}\text { Size class } \\
(\mu \mathrm{m})\end{array}$ & $\begin{array}{c}\text { Number } \\
\text { in water }\end{array}$ & $\begin{array}{c}\text { Number } \\
\text { in sediment }\end{array}$ & $\begin{array}{c}\text { Model } \\
\text { source pool }\end{array}$ & $\begin{array}{c}\text { Sample random water } \\
\text { column distribution }\end{array}$ \\
\hline $251-271$ & 403 & 950 & 1353 & 413 \\
$272-292$ & 224 & 590 & 814 & 247 \\
$293-313$ & 148 & 315 & 463 & 134 \\
$314-334$ & 54 & 80 & 49 & 43 \\
$335-355$ & 19 & 30 & 3 & 17 \\
$356-376$ & 3 & 5 & 1 & 0 \\
$377-397$ & 1 & 0 & 2822 & 0 \\
$398-418$ & 852 & 1970 & 552 \\
Total & & & 5 \\
\hline
\end{tabular}


Table 2. Numbers $\left(100 \mathrm{~cm}^{-2}\right)$ of migrating and non-migrating Zausodes arenicolus and total harpacticoids collected during postsunset periods on various dates in a Tampa Bay, Florida, subtidal seagrass habitat. Data are from Walters \& Bell (1986), Walters (1987) and the present study

\begin{tabular}{|c|c|c|c|c|c|c|c|}
\hline \multirow[t]{2}{*}{ Date } & \multicolumn{2}{|c|}{ Z. arenicolus } & \multicolumn{2}{|c|}{ Total harpacticoids } & \multirow{2}{*}{$\begin{array}{c}\% \\
\text { Z. arenicolus } \\
\text { of total }\end{array}$} & \multirow{2}{*}{$\begin{array}{c}\% \\
\begin{array}{c}\% . \\
\text { mignicolus }\end{array} \\
\text { migring }\end{array}$} & \multirow{2}{*}{$\begin{array}{l}\% \text { Total } \\
\text { migrating }\end{array}$} \\
\hline & Migrating & $\begin{array}{c}\text { Non- } \\
\text { migrating }\end{array}$ & Migrating & $\begin{array}{c}\text { Non- } \\
\text { migrating }\end{array}$ & & & \\
\hline \multicolumn{8}{|c|}{ Walters \& Bell (1986) } \\
\hline Nov 1981 & 38 & 132 & 711 & 2106 & 6.0 & 22.4 & 25.2 \\
\hline \multicolumn{8}{|c|}{ Walters (1987) } \\
\hline Nov 1983 & 22 & 416 & 281 & 2695 & 16.2 & 5.0 & 9.4 \\
\hline \multicolumn{8}{|c|}{ Present study } \\
\hline Nov 1983 & 242 & 957 & 555 & 5653 & 19.3 & 20.1 & 8.9 \\
\hline Nov 1984 & 69 & 1261 & 355 & 6118 & 21.0 & 5.2 & 5.5 \\
\hline
\end{tabular}

Table 3. Zausodes arenicolus. Percentages of various population characteristics of copepods collected in 1983 and 1984

\begin{tabular}{|c|c|c|c|c|}
\hline & \multicolumn{2}{|c|}{1983} & \multicolumn{2}{|c|}{1984} \\
\hline & Water & Sediment & Water & Sediment \\
\hline Female & 35 & 47 & 42 & 51 \\
\hline Male & 46 & 29 & 38 & 25 \\
\hline Copepodite & 19 & 24 & 20 & 24 \\
\hline $\begin{array}{l}\text { Gravid female } \\
\text { (as \% of all females) }\end{array}$ & 17 & 15 & 7 & 5 \\
\hline $\begin{array}{l}\text { Clasping } \\
\text { (as \% of total Zausodes) }\end{array}$ & 11 & 13 & 17 & 6 \\
\hline
\end{tabular}

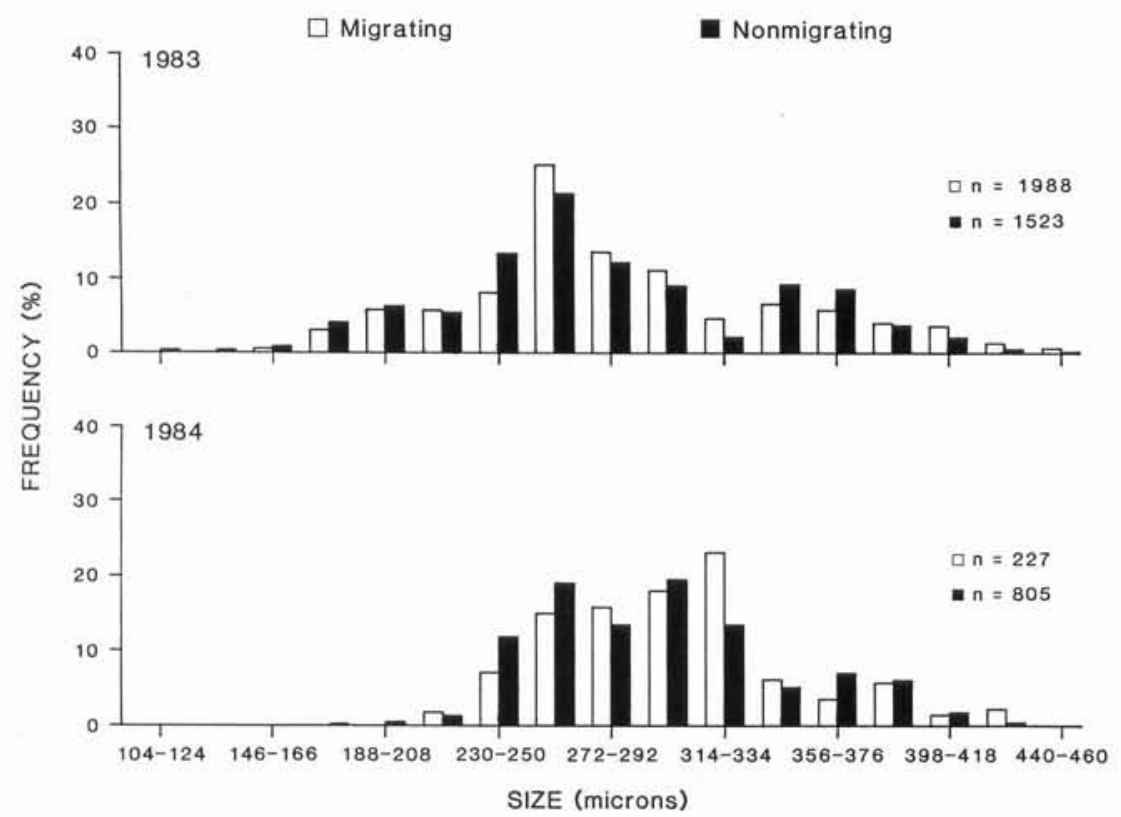

Fig. 1. Zausodes arenicolus. Size frequency distributions of migrating and non-migrating copepods collected in November 1983 and 1984. Frequency is expressed as the percentage in each size class. n: actual numbers collected

ting sizes while accounting for only $14.9 \%$ of nonmigrating females. Water column and sediment size frequency distributions of males (K-S, Z $=1.117, \mathrm{p}>$ 0.05 ) and copepodites (K-S, $Z=1.135, p>0.05)$ col- lected in 1983 were not significantly different. When the 1984 data were examined by sex and stage, patterns of size migrations could be predicted from the overall size distribution (Fig. 1), with no differences 
Fig. 2. Zausodes arenicolus. Size frequency distributions of females, males and copepodites collected in November 1983. Frequency is expressed as the percentage in each size class (n represents measured copepods used in analyses and does not equal the total in Fig. 1 because of difficulties in sex or stage classification)

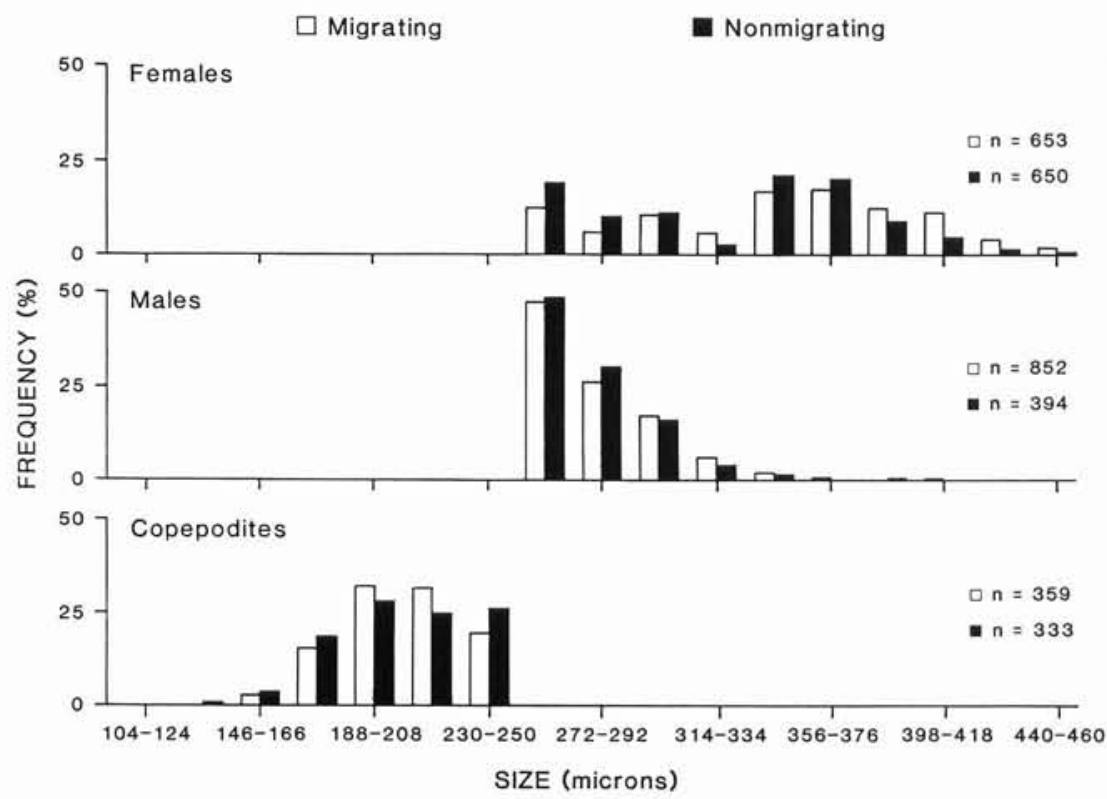

between migrating and non-migrating females (K-S, Z $=0.559, \mathrm{p}>0.05)$, males $(\mathrm{K}-\mathrm{S}, \mathrm{Z}=0.955, \mathrm{p}>0.05)$ or copepodites (K-S, $\mathrm{Z}=1.114, \mathrm{p}>0.05)$.

Results of comparisons between actual and nullmodel-generated size distributions indicated that the size distribution of migrating Zausodes arenicolus collected in 1983 was significantly different from randomly generated water column distributions in 10 out of 10 runs of the model (Table 4). The actual 1984 size distribution of migrating $Z$. arenicolus, however, was indistinguishable from randomly generated size distributions in 9 out of 10 trials. We also compared observed and null-model-generated size distributions for the 1983 data catagorized by sex and stage. The distribution of migrating females was significantly different from randomly generated distributions; however migrating male and copepodite distributions were indistinguishable from distributions generated by the null model (Table 4).

Table 4. Summary of results for comparisons of actual and null-model-generated water column size frequency distributions in 1983 and 1984. Listed are the number of times out of 10 that the null hypothesis was rejected. $\left(\mathrm{H}_{\mathrm{o}}\right.$ : observed water column size frequency distribution not significantly different from randomly generated distribution)

\begin{tabular}{|clc|}
\hline \multirow{2}{*}{ Year } & Group & Model results \\
\hline \multirow{2}{*}{1983} & Total distribution & 10 \\
& Females & 10 \\
& Males & 0 \\
\multirow{2}{*}{1984} & Copepodites & 0 \\
& Total distribution & 1 \\
\hline
\end{tabular}

\section{DISCUSSION}

Size significantly influenced the migration of Zausodes arenicolus only in 1983 and the overall effect resulted from significantly larger females entering the water column. Migrations of males and copepodites in 1983 and any sex or stage in 1984 were not influenced by size. The 1983 migration of larger females into the water column was also significantly different from that predicted by the null model, implying that deterministic forces are affecting female migrations. Different sized males and copepodites appeared to migrate randomly into the water column on both dates.

The non-random migration of larger females in 1983 is inconsistent with the hypothesis that harpacticoid migration is linked to mating activity (see Bell et al. 1988). Precocious clasping, grasping of subadult stage IV or V females by adult males, is typical in Zausodes arenicolus (Kern et al. 1984) suggesting that clasping pairs, adult males and smaller female copepodites should predominate in the water column if migration is linked to mating. Clasping pairs were not found more commonly in the water in 1983, and while adult males are predominant migrators, it is the larger size classes of females that were more common in the water column in 1983. The migration of larger females and the observation that larger, gravid females are more common in the water column compared to the sediment (Service pers. obs.) suggests that female migration may be linked to other aspects of reproductive behavior, such as naupliar release. A more detailed study of reproduction in $Z$. arenicolus is required to test the naupliar release hypothesis.

The singular 1983 occurrence of significantly larger female migrators may be related to variability in the 
year-to-year reproductive cycle of Zausodes arenicolus. Compared to 1984, a greater percentage of the $Z$. arenicolus population was gravid in both the water column and sediment in 1983. Reduced numbers of gravid females and an increase in the percentage of clasping pairs in the water column suggests that the 1984 population was in an earlier phase of population growth. It is possible that larger females in the appropriate stage of the reproductive cycle were not available in 1984, resulting in the lack of a significant size difference in female migrations.

Null or neutral models have been used to examine numerous patterns in biology (Gilpin \& Diamond 1982, Matthews 1982, Silvertown 1983, Simberloff 1984, Gotelli et al. 1987, Tokeshi \& Townsend 1987, Clarke 1988, Lambshead \& Platt 1988), but few investigations of single species population processes, as in the current study, have employed null models. The utility of null models has remained controversial (Harvey et al. 1983, Nitecki \& Hoffman 1987), and a number of potential problems with the approach are illustrated by studies attempting to detect the effects of competition in species co-occurrence data (Connor \& Simberloff 1979 , 1983, 1984, Diamond \& Gilpin 1982, Gilpin \& Diamond 1982, 1984). Formulation of a realistic source pool, selection of unlikely species combinations, and construction of an unbiased model that does not reflect past competitive interactions or account for the special properties of individual species all confound the multispecies use of null models. If competition, or other multispecies processes, is not the major focus of a study, deciding on an appropriate null model and accompanying source pool is less of a problem.

Examining patterns within populations avoids many of the problems associated with multispecies null models. Single species models appear to require fewer assumptions compared to models analyzing community processes. Unreasonable combinations generated during Monte Carlo simulations from source pools containing species that naturally do not co-occur are unlikely in population level analyses. In the present study, the null model combined all sizes of Zausodes arenicolus since all sizes typically co-occur in the sediments. Our approach also avoids problems concerning construction of the source pool from which random draws are taken. The size source pool is readily identifiable and, unlike models attempting to detect patterns in multi-species distributions, there is no question as to the origins of migrating individuals. Sample sizes were adequate to represent relative size frequency distributions and emergence traps were sealed to the sediment surface.

Comparison of actual with null-model-generated size distributions of migrating Zausodes arenicolus suggested that statistical differences in the sizes of migrating individuals in 1983 resulted from a real difference in behavior. We can conclude that the migration of larger females was not a chance event and probably resulted from some deterministic cause (i.e. naupliar release). Null model results increase our confidence in stating that size, at times, influences $Z$. arenicolus migrations. Although null model results corrorborated initial K-S findings that significantly larger females migrated, many instances exist where use of null models leads to different interpretations (Rathke 1984, Simberloff 1984, Gotelli et al. 1987). Such studies emphasize that it is not always necessary to ascribe a deterministic cause to a pattern when a stochastic one will suffice.

Null models can have an important role in exploratory data analysis; however they generally have been underutilized in marine studies (but see Platt \& Lambshead 1985, McCoy et al. 1986, Gotelli et al. 1987, Clarke 1988, Lambshead \& Platt 1988, Meyers et al. 1988). Properly constructed null models identify patterns that can be statistically distinguished from random and pinpoint areas for future experimental research. Null model results in the present study suggest that the size distribution of migrating females was not influenced solely by stochastic factors. Experimental investigations of deterministic factors affecting the size distribution of migrating Zausodes arenicolus are warranted.

Acknowledgements. We thank D. Allen, S. Bell, M. Bergmans, B. Coull, R. Feller, E. McCoy, P. Rothlisberg and 2 anonymous reviewers for comments on earlier drafts of the manuscript. The cooperation of the Pinellas County Parks Department in allowing $24 \mathrm{~h}$ access to the field site was greatly appreciated. Partial support during this study was provided by NSF grant OCE 80017 261A from Biological Oceanography, S.S. Bell principle investigator, the University of South Carolina Marine Science Program, a Fullbright Fellowship to K. Walters and the Sapelo Island Research Foundation.

\section{LITERATURE CITED}

Allan, J. D. (1978). Trout predation and the size composition of drift. Limnol. Oceanogr. 23: 1231-1237

Bell, S. S., Hicks, G. R. F., Walters, K. (1988). Active swimming in meiobenthic copepods of seagrass beds: species patterns and role in reproductive behavior Mar. Biol. 98: 351-358

Bell, S. S., Walters, K., Hall, M. O. (1987). Habitat utilization by harpacticoid copepods: a morphometric approach. Mar. Ecol. Prog. Ser. 35: 59-64

Clarke, R. D. (1988). Chance and order in determining fishspecies composition on small coral patches. J. exp. mar. Biol. Ecol. 115: 197-212

Colwell, R. K., Winkler, D. W. (1983). A null model for null models in biogeography. In: Strong, D. R., Jr, Simberloff, D., Abele, L. G., Thistle, A. B. (eds.) Ecological communities: conceptual issues and the evidence. Princeton University Press, Princeton, p. 344-359

Connor, E. F., Simberloff, D. (1979). The assembly of species communities: chance or competition? Ecology 60: 1132-1140

Connor, E. F., Simberloff, D. (1983). Interspecific competition 
and species co-occurrence patterns on islands: null models and the evaluations of the evidence. Oikos 41: 455-465

Connor, E. F., Simberloff, D. (1984). Neutral models of species co-occurrence patterns. In: Strong, D. R., Jr, Simberloff, D., Abele, L. G., Thistle, A. B. (eds.) Ecological communities: conceptual issues and the evidence. Princeton University Press, Princeton, p. 316-331

Diamond, J. M., Gilpin, M. E. (1982). Examination of the 'null' model of Connor and Simberloff for species co-occurrences on islands. Oecologia (Berl.) 52: 64-74

Epifanio, C. E. (1988). Transport of invertebrate larvae between estuaries and the continental shelf. Am. Fish. Soc. Symp. 3: 104-114

Fancett, M. S., Kimmerer, W. J. (1985). Vertical migration of the demersal copepod Pseudodiaptomus as a means of predator avoidence. J. exp. mar. Biol. Ecol. 88: 31-44

Gilpin, M. E., Diamond, J. M. (1982). Factors contributing to non-randomness in species co-occurrences on islands. Oecologia (Berl.) 52: 75-84

Gilpin, M. E., Diamond, J. M. (1984). Are species co-occurrences on islands non-random and are null hypotheses useful in community ecology? In: Strong, D. R., Jr, Simberloff, D., Abele, L. G., Thistle, A. B. (eds.) Ecological communities: conceptual issues and the evidence. Princeton University Press, Princeton, p. 297-315

Gotelli, N. J., Lewis, F. G., Young, C. M. (1987). Body-size differences in a colonizing amphipod-mollusc assemblage. Oecologia (Berl.) 72: 104-108.

Grad, G., Maly, E. J. (1988). Sex size ratios and their influence on mating success in a calanoid copepod. Limnol. Oceanogr. 33: 1629-1634

Harvey, P. H., Colwell, R. K., Silvertown, J. W., May, R. M. (1983). Null models in ecology. A. Rev. Ecol. Syst. 14: 189-211

Huntley, M. A., Brooks, E. R. (1982). Effects of age and food availability on diel vertical migration of Calanus pacificus. Mar. Biol. 71: 23-31

Kern, J. C., Edwards, N. A., Bell, S. S. (1984). Precocious clasping of early copepodite stages: a common occurrence in Zausodes arenicolus Wilson (Copepoda: Harpacticoida) J. crust. Biol. 4: 261-265

Lambshead, P. J. D., Platt, H. M. (1988). Analyzing disturbance with the Ewens/Caswell neutral model: theoretical review and practical assessment. Mar. Ecol. Prog. Ser. 43: $31-41$

Lampert, W. (1987). Vertical migration of freshwater zooplankton: indirect effects of vertebrate predators on algal communities. In: Kerfoot, W. C., Sih, A. (eds.) Predation: direct and indirect impacts on aquatic communites. University Press of New England, London, p. 291-299

Lawrence, W. S. (1987). Dispersal: an alternative mating tactic conditional on sex ratio and body size. Behav. Ecol. Sociobiol. 21: 367-373

Malmqvist, B., Sjostrom, P. (1987), Stream drift as a consequence of disturbance by invertebrate predators. Oecologia (Berl.) 74: 396-403

Matthews, W. J. (1982). Small fish community structure in Ozark streams. Am. Mid. Nat. 107: 42-54

McCoy, E. D., Bell, S. S., Walters, K. (1986). Identifying biotic boundaries along environmental gradients. Ecology 67: 749-759

Meyers, M. B., Powell, E. N., Fossing, H. (1988). Movement of oxybiotic and thiobiotic meiofauna in response to changes in pore-water oxygen and sulfide gradients around macroinfaunal tubes. Mar. Biol. 98: 395-414

This article was presented by Dr R. M. Warwick, Plymouth, UK
Newman, R. M., Waters, T. M. (1984). Size selective predation on Gammarus pseuolimnaeus by trout and sculpins. Ecology 65: 1535-1545

Nitecki, M. H., Hoffman, A. (1987). Neutral models in biology. Oxford University Press, New York

Platt, H. M., Lambshead, P. J. D. (1985). Neutral model analysis of patterns of marine benthic species diversity. Mar. Ecol. Prog. Ser. 24: 75-81

Preece, G. S. (1971). The swimming rhythm of Bathyporeia pilosa. J. mar. biol. Ass. UK 51: 777-791

Rathke, B. J. (1984). Patterns of flowering phenologies: testability and casual inference using a random model. In: Strong, D. R., Jr, Simberloff, D., Abele, L. G., Thistle, A. B. (eds.) Ecological communities: conceptual issues and the evidence. Princeton University Press, Princeton, p. 383-396

Robertson, A. I., Howard, R. K. (1978). Diel trophic interactions between vertically migrating zooplankton and their fish predators in an eelgrass community. Mar. Biol. 48: 207-213

Rothlisberg, P. C. (1982). Vertical migration and its effects on dispersal of penaeid shrimp larvae in the Gulf of Carpentaria, Australia. Fish. Bull. U.S. 80: 541-554

Silvertown, J. W. (1983). The distribution of plants in limestone pavement: tests of species interactions and niche separation against null hypotheses. J. Ecol. 71: 819-828

Simberloff, D. (1984). Properties of coexisting bird species in two archipelagoes. In: Strong, D. R., Simberloff, D., Abele, L. G., Thistle, A. B. (eds.) Ecological communities: conceptual issues and the evidence. Princeton University Press, Princeton, p. 234-253

Sokal, R. R., Rohlf, F. J. (1981). Biometry, 2nd edn. W.H. Freeman and Co., San Francisco

Strong, D. R. (1980). Null hypothesses in ecology. Synthese 43 271-285

Sulkin, S. D. (1984). Behavioral basis of depth regulation in the larvae of brachyuran crabs. Mar. Ecol. Prog. Ser. 15: 181-205

Tokeshi, M., Townsend, C. R. (1987). Random patch formation and weak competition: coexistence in an epiphytic chironomid community J. Anim. Ecol. 56: 833-845

Walters, K. (1987). Experimental investigations of vertically migrating meiofaunal populations in subtropical sand and seagrass habitats. $\mathrm{Ph}$. D. dissertation, University of South Florida, Tampa

Walters, K. (1988). Diel vertical migration of sediment-associated meiofauna in subtropical sand and seagrass habitats J. exp. mar. Biol. Ecol. 117: 169-186

Walters, K., Bell, S, S. (1986). Diel patterns of active vertical migration in seagrass meiofauna. Mar. Ecol. Prog. Ser. 34: 95-103

Ward, P. I. (1983). Advantages and a disadvantage of large size for male Gammarus pulex (Crustacea: Amphipoda). Behav. Ecol. Sociobiol. 14: 69-76

Wieser, W. (1960). Benthic studies in Buzzard's Bay. II. The meiofauna. Limnol. Oceanogr. 5: 121-127

Williams, C. B. (1947). The generic relations of species in small ecological communities. J. Anim. Ecol. 16: 11-18

Williams, A. B., Bynum, H. (1972). A ten year study of meroplankton in North Carolina estuaries. Chesapeake Sci. 13: 175-192

Williams, R., Fragopoulu, N. (1985). Vertical distribution and nocturnal migration of Nyctiphanes couchi (Crustacea: Euphausiacea) in relation to the summer thermocline in the Celtic Sea. Mar. Biol. 89: 257-262 